\title{
The Odorant Receptor-Dependent Role of Olfactory Marker Protein in Olfactory Receptor Neurons
}

\author{
Michele Dibattista and Johannes Reisert \\ Monell Chemical Senses Center, Philadelphia, Pennsylvania 19104-3308
}

Olfactory receptor neurons (ORNs) in the nasal cavity detect and transduce odorants into action potentials to be conveyed to the olfactory bulb. Odorants are delivered to ORNs via the inhaled air at breathing frequencies that can vary from 2 to $10 \mathrm{~Hz}$ in the mouse. Thus olfactory transduction should occur at sufficient speed such that it can accommodate repetitive and frequent stimulation. Activation of odorant receptors (ORs) leads to adenylyl cyclase III activation, cAMP increase, and opening of cyclic nucleotide-gated channels. This makes the kinetic regulation of cAMP one of the important determinants for the response time course. We addressed the dynamic regulation of cAMP during the odorant response and examined how basal levels of cAMP are controlled. The latter is particularly relevant as basal cAMP depends on the basal activity of the expressed OR and thus varies across ORNs. We found that olfactory marker protein (OMP), a protein expressed in mature ORNs, controls both basal and odorant-induced cAMP levels in an OR-dependent manner. Lack of OMP increases basal cAMP, thus abolishing differences in basal cAMP levels between ORNs expressing different ORs. Moreover, OMP speeds up signal transduction for ORNs to better synchronize their output with high-frequency stimulation and to perceive brief stimuli. Last, OMP also steepens the dose-response relation to improve concentration coding although at the cost of losing responses to weak stimuli. We conclude that OMP plays a key regulatory role in ORN physiology by controlling multiple facets of the odorant response.

Key words: olfactory; olfactory receptor neurons; olfactory signal transduction

\section{Significance Statement}

Odorant receptors (ORs) form the largest family of G-protein-coupled receptors in mammals and are expressed in olfactory receptor neurons (ORNs). In this paper we show how the olfactory system ensures that monogenic expression of ORs dictates the response profile and the basal noise of ORNs. Olfactory marker protein (OMP), a protein long known to be expressed in mature ORNs, is responsible for controlling appropriate cAMP homeostasis and dynamics to ensure that the expressed OR is the main source of noise. In addition, OMP regulates the dynamic range of ORNs in an OR-dependent way to allow for concentrationdependent odor coding.

\section{Introduction}

The olfactory system gathers information from many distinct odorants present at a given point in time and space. For odorants

Received Nov. 23, 2015; revised Jan. 25, 2016; accepted Feb. 4, 2016.

Author contributions: M.D. and J.R. designed research; M.D. performed research; M.D. and J.R. analyzed data; M.D. and J.R. wrote the paper.

This work was supported by National Institutes of Health (NIH) Grant DC009613 (to J.R.) and by Grant G200D020296 (for infrastructure improvement at the Monell Chemical Senses Center). Immunohistochemistry and confocal microscopy was performed at the Monell Histology and Cellular Localization Core and genotyping was performed at the Monell Genotyping and DNA/RNA Analysis Core, which are supported, in part, by funding from the NIH National Institute on Deafness and Other Communication Disorders Core Grant 1P30DC011735-01. The authors thank Drs. Graeme Lowe, Anna Menini, and Simone Pifferi for helpful discussions and comments on the manuscript; Dr. Kazushige Touhara for providing the mOR-EG-GFP mice; and Amanda Miller for expert technical assistance. We are also grateful to Dr. Frank Margolis for commenting on the manuscript and providing the OMP KO mice.

The authors declare no competing financial interests.

Correspondence should be addressed to Johannes Reisert at the above address. E-mail: jreisert@monell.org.

M. Dibattista's present address: Department of Basic Medical Sciences, Neuroscience and Sensory Organs, University of Bari "A. Moro," Bari, Italy. to be detected by olfactory receptor neurons (ORNs) in the nasal cavity, mammals sample environmental odors by changing their breathing frequency between 2 and $10 \mathrm{~Hz}$ (Youngentob et al., 1987; Tankersley et al., 1994; Kepecs et al., 2007). ORNs should then be tuned to ensure an appropriate range of odorant sensitivity and have kinetic properties that allow them to fire action potentials (APs) to reliably encode for natural stimuli in the behaving animal.

Odorants bind to olfactory receptors (ORs) expressed in the cilia of ORNs. ORs are G-protein-coupled receptors expressed in a monogenic fashion (Buck and Axel, 1991; Malnic et al., 1999) so that each ORN expresses one OR type among $\sim 1000$ in the mouse genome. Activated ORs initiate signal transduction by activating the G-protein Golf (Jones and Reed, 1989), which in turn activates adenylyl cyclase type III (AC3; Bakalyar and Reed, 
1990) to facilitate the conversion of ATP to cAMP. The ciliary cAMP increase opens the olfactory cyclic nucleotide-gated (CNG) channel (Nakamura and Gold, 1987; Firestein et al., 1991) and influx of $\mathrm{Na}^{+}$and $\mathrm{Ca}^{2+}$ (Dzeja et al., 1999) causes ORN depolarization. $\mathrm{Ca}^{2+}$ triggers the activation of the second olfactory transduction channel, an excitatory $\mathrm{Ca}^{2+}$-activated $\mathrm{Cl}^{-}$ channel TMEM16B/ANO2 (Kleene, 1993; Lowe and Gold, 1993; Stephan et al., 2009; Hengl et al., 2010; Rasche et al., 2010; Sagheddu et al., 2010; Billig et al., 2011). Transduction leads to the generation of APs to convey odor information to the olfactory bulb (OB). Mammalian ORNs fire APs at increasing frequency as the odor concentration increases, while the number of fired APs first increases up to intermediate odor concentrations and then decreases at higher concentrations (Gesteland and Sigwart, 1977; Reisert and Matthews, 2001; Rospars et al., 2008).

For the odorant response to terminate, cAMP and $\mathrm{Ca}^{2+}$ must return to basal levels for $\mathrm{CNG}$ and $\mathrm{Cl}^{-}$channels to close. Ciliary $\mathrm{Ca}^{2+}$ reduction is achieved by a Na${ }^{+} / \mathrm{Ca}^{2+}$ extrusion (NCKX4; Stephan et al., 2012). Interestingly, the rate of cAMP degradation is not controlled by the olfactory phosphodiesterases (PDEs) $1 \mathrm{C}$ and $4 \mathrm{~A}$ as neither PDE contributes significantly to response termination (Boccaccio et al., 2006; Cygnar and Zhao, 2009).

So what mechanisms control olfactory kinetics? Olfactory marker protein (OMP), a protein thought to be exclusively expressed in mature ORNs (Margolis, 1972), has been shown to be involved in olfactory kinetics. Interestingly, OMP was recently found to be expressed in other nonolfactory tissues, often with ORs and AC3 (Kang et al., 2015). Electro-olfactograms from OMP knock-out (KO) mice have slower onset and decay kinetics compared with wild type (WT; Buiakova et al., 1996). Single-cell recordings from isolated OMP KO ORNs showed that ORNs' ability to fire APs was also altered (Reisert et al., 2007). OMP speeds up signal transduction by acting upstream of cAMP production, probably at the level of AC3. Recordings from ORNs expressing the MOR23 OR showed that OMP KO ORNs have a broadened odorant selectivity (Lee et al., 2011), which probably lead to synaptic inputs to more glomeruli in the OB (Kass et al., 2013). Behaviorally, OMP KO mice have deficits in their ability to detect and discriminate odorants (Youngentob and Margolis, 1999; Youngentob et al., 2001, 2003).

Here we investigate how OMP affects ORN physiology and limits the speed of olfactory transduction. We found that OMP affects transduction kinetics in an OR-dependent manner, most likely depending on the basal activity of the OR expressed in a given ORN (Reisert, 2010; Nakashima et al., 2013). Additionally, the slow response kinetics of OMP KO ORNs severely dampens their ability to reliably encode odorant stimuli at higher stimulus frequencies. Finally, we show that OMP has a thresholding function in ORNs that can "filter out" stimuli at lower concentrations and endow ORNs with a narrow dynamic range.

\section{Materials and Methods}

Animals. Mice (2 to 6 months old of either sex) were killed using $\mathrm{CO}_{2}$ followed by decapitation as approved by the Monell Chemical Senses Center Institutional Animal Care and Use Committee, conforming to National Institutes of Health guidelines. The olfactory epithelium was removed from the nasal cavity and stored in oxygenated Ringer's solution at $4^{\circ} \mathrm{C}$ until use. A small piece of olfactory epithelium was dissected out from the underlying cartilage, placed in an Eppendorf tube containing $200 \mu \mathrm{l}$ of Ringer's solution, and gently vortexed (Reisert and Matthews, 2001; Ponissery Saidu et al., 2012). The resulting cell suspension containing isolated ORNs was then transferred to a recording chamber on an inverted microscope and allowed to settle for $20 \mathrm{~min}$ before bath perfusion started. Isolated ORNs were recognized by using fluorescence optics. The GFP-labeled M71 mouse line was generated by inserting IRES-tauGFP after the mouse M71 coding sequences (Bozza et al., 2002). The mOR-EG-GFP line was made using a transgene consisting of $3.0 \mathrm{~kb}$ upstream of the mOR (mouse olfactory receptor)-EG transcription start site followed by mOR-EG-IRES-gapEGFP (Oka et al., 2006). These mouse lines were crossed with the OMP KO line (Buiakova et al., 1996) and bred to obtain OMP WT and KO mice in a M71-IRES-tauGFP homozygous and mOR-EG-IRES-gapEGFP hemizygous background respectively.

Suction pipette recordings. We used the suction-pipette technique (Baylor et al., 1980) to record from isolated ORNs (Lowe and Gold, 1991; Ponissery Saidu et al., 2012). The suction-pipette technique provides superbly long and stable recording durations. The cell body of an isolated mouse ORN was drawn into the tip of the recording pipette, leaving the cilia exposed to the bath solution and accessible to solution changes. In this recording configuration, the recorded current (termed suction current) represented the transduction current, which enters at the cilia and exits at the cell body. In addition, since the intracellular voltage is free to vary, ORNs generate APs at the onset of the suction current, which are also recorded as typically biphasic, fast capacitance current transients. The suction current was filtered at DC $5000 \mathrm{~Hz}$ ( $-3 \mathrm{~dB}$, eight-pole Bessel filter), a bandwidth wide enough to faithfully record the fast APs. The slow receptor current was isolated by filtering the suction current with a bandwidth of DC $50 \mathrm{~Hz}$ ( $-3 \mathrm{~dB}$, eight-pole Bessel filter). The recorded suction current was sampled at $10 \mathrm{kHz}$. Currents were recorded with a Warner PC-501A patch-clamp amplifier, digitized using a Power1401 II analog-to-digital converter and Signal acquisition software (Cambridge Electronic Design).

Solutions and solution exchange. Mammalian Ringer's solution contained (in mM) the following: $140 \mathrm{NaCl}, 5 \mathrm{KCl}, 1 \mathrm{MgCl}_{2}, 2 \mathrm{CaCl}_{2}, 0.01$ EDTA, 10 HEPES, and 10 glucose. The $\mathrm{pH}$ was adjusted to 7.5 with $\mathrm{NaOH}$. Acetophenone (the ligand of the M71 odorant receptor) and eugenol (the ligand of the mOR-EG odorant receptor) $20 \mathrm{~mm}$ stock solution in dimethyl sulfoxide (DMSO) were prepared fresh the day of the experiments. The odorant solutions were prepared by dilution in Ringer's solution to the final concentration. Niflumic acid and 3-isobutyl-1-methylxanthine (IBMX) were used at concentrations of 300 and $1 \mathrm{~mm}$, respectively, by dissolving them directly into Ringer's solution without the use of DMSO. All chemicals were purchased from SigmaAldrich. The forskolin analog NKH 477 (Tocris Bioscience) at $40 \mu \mathrm{M}$ was dissolved in Ringer's solution and freshly prepared the day of the experiment.

Fast solution changes and odorant exposures were achieved by transferring the tip of the recording pipette containing the ORN across the interface of neighboring streams of solutions using the Perfusion FastStep solution changer (Warner Instrument). Solution exchange was complete within $7 \mathrm{~ms}$, as determined from the $10-90 \%$ rise or fall time of a junction current, which was elicited by stepping between solutions of different ionic content. All experiments were performed at mammalian body temperature $\left(37^{\circ} \mathrm{C}\right)$. Solutions were heated just before entering the solution changer by a solution heater based on work by Matthews (1999).

Data analysis. The basal firing rate was determined from $30 \mathrm{~s}$ recordings taken at the beginning shortly after establishing the recording configuration. Typically the ORN had only been exposed to a single $1 \mathrm{~s}$ exposure of its respective ligand to avoid possible adaptation effects. All APs over the $30 \mathrm{~s}$ period were counted, and this number was divided by $30 \mathrm{~s}$ to obtain the mean basal spike frequency. The frequency composition in the absence of stimulation and in the presence of niflumic acid was evaluated by performing power spectra analysis on single $30 \mathrm{~s}$ recordings using IGOR (Wavemetrics) and Clampfit Software (Reisert, 2010). The variance was calculated as the difference of the power spectra in the absence and presence of niflumic acid of unfiltered traces $(0-5000 \mathrm{~Hz})$ and subsequently integrated from 0.3 (used as cutoff to exclude slow baseline drifts) to $50 \mathrm{~Hz}$.

Data are presented as mean \pm SE (SEM). Statistical tests are specified in the text and were performed using R software.

Immunohistochemistry. Mice were anesthetized with avertin $(12.5 \mathrm{mg} /$ $\mathrm{ml}$ ) and intracardiac perfusion was performed. First, animals were perfused with PBS followed by ice-cold paraformaldehyde $4 \% \mathrm{w} / \mathrm{v}$ in PBS, 
A

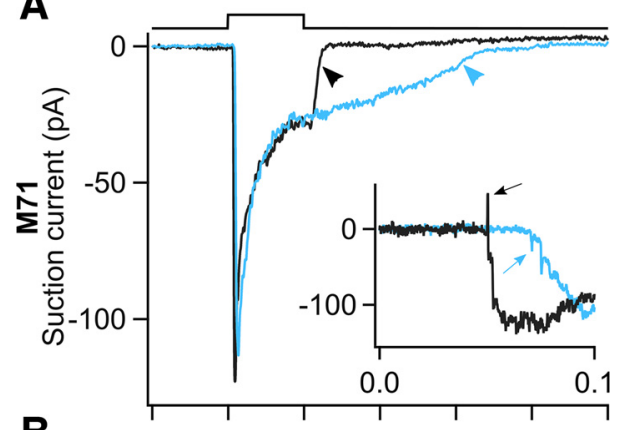

B

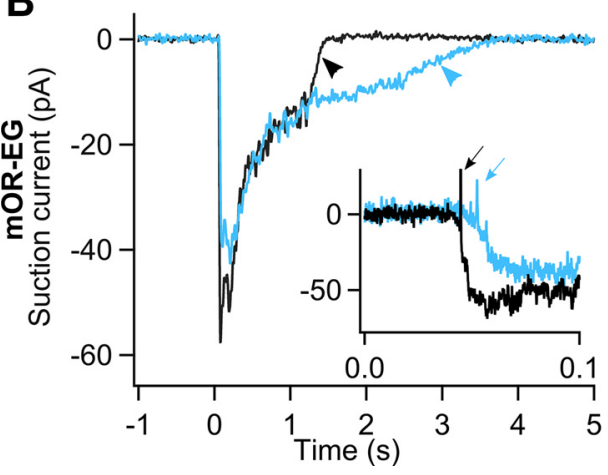

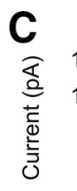

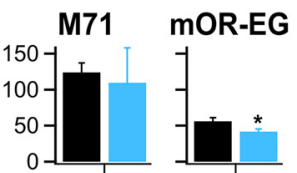

造
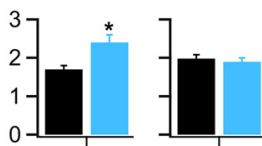

疍
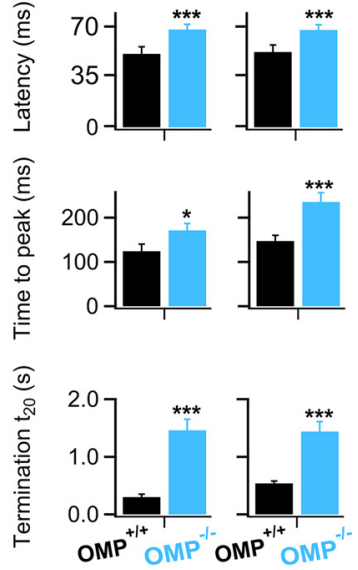

Figure 1. Odorant-receptor-dependent changes in odorant responses in OMP KO ORNs. $A, B$, Responses to $1 \mathrm{~s}$ stimulations of $100 \mu \mathrm{M}$ acetophenone or eugenol from M71-GFP-expressing or mOR-EG-expressing ORNs respectively of OMP WTs (black trace) and OMP KOs (blue trace). Inset shows the rising phase of the receptor currents filtered at $0-5 \mathrm{kHz}$ to display APs (arrows). $\boldsymbol{C}$, Average data from OMP WT (black bars) and KO (blue bars) M71-expressing (left) and mOR-EG-expressing (right) ORNs. Peak current, number of APs, response latency measured as the delay between odorant onset and arrival of the first AP, time to peak (the time between stimulus onset and the time the response reaches its maximum), and $t_{20}$, a measure of response termination (arrowheads). $n=13-17$ ORNs for M71 ORNs and $n=48-65$ ORNs for mOR-EG ORNs. ${ }^{*} p<0.05$; ${ }^{* * *} p<0.005$, unpaired Student's $t$ test. All data are expressed as mean \pm SEM.

$\mathrm{pH}$ 7.4. The $\mathrm{OB}$ was extracted and postfixed for $2 \mathrm{~h}$. Tissue was then placed in $30 \%(\mathrm{w} / \mathrm{v})$ sucrose and left overnight at $4^{\circ} \mathrm{C}$ for cryoprotection. Twelve-micrometer-thick sagittal sections were cut on a cryostat and stored at $-20^{\circ} \mathrm{C}$. Tissue sections were incubated with $0.5 \%$ SDS (v/v) in PBS for $30 \mathrm{~min}$ for antigen retrieval, then incubated in blocking solution (3\% BSA, 0.3\% Triton X-100 in PBS) for $90 \mathrm{~min}$, and incubated overnight at $4^{\circ} \mathrm{C}$ with goat anti-neuropilin 1 (1:100; AF566, R\&D Systems) primary antibodies diluted in blocking solution. After rinsing in $0.1 \%$ (v/v) Tween 20 in PBS, sections were incubated with Alexa donkey anti-goat 555 secondary antibodies in $0.1 \%$ Tween 20 in PBS for $2 \mathrm{~h}$ at room temperature and washed. Four'-6-diamidino-2-phenylindole $(0.1$ $\mu \mathrm{g} \mathrm{ml}^{-1}$ ) was used to counter-stain nuclei. Tissue sections were incubated for $30 \mathrm{~min}$ then washed and mounted with Vectashield (Vector Laboratories).

All images were taken with Leica SP2 confocal microscope at a resolution of $1024 \times 1024$ pixels. Only images in Figure 8 were manipulated by cropping and adjusting brightness and contrast with ImageJ (National Institutes of Health) for the purpose of illustration. Intensity values were obtained by averaging pixel intensities in each glomerulus (defined as the stained area surrounded by periglomerular cells) and subtracting the background defined as the intensity values of an arbitrary region of interest in the external plexiform layer.

\section{Results}

The lack of OMP alters the kinetics and amplitude of odorant responses

We sought to determine how OMP affects the odorant response in ORNs expressing known odorant receptors. We generated two OMP KO lines that also expressed GFP with either the M71 or the mOR-EG receptor with acetophenone and eugenol being the respective ligands (Bozza et al., 2002; Kajiya et al., 2001). Those two
ORs were selected because they have different rates of constitutive activity (Reisert, 2010; Nakashima et al., 2013) that drives basal levels of transduction current fluctuations with consequent AP firing. ORNs expressing M71 or the mOR-EG show high and low levels of basal noise respectively (Reisert, 2010; Connelly et al., 2013; Nakashima et al., 2013).

In both M71 and mOR-EG WT ORNs, a 1 s odorant exposure generated a rapidly increasing current response, which decayed after reaching its peak and terminated quickly once odorant exposure ceased (Fig. $1 A, B$, black traces). In OMP KO ORNs, the response kinetics (Fig. $1 A, B$, blue traces) were slower in both M71 and mOR-EG OMP KO ORNs. The slowed response kinetics in OMP KO mice is in agreement with what was shown previously in randomly picked ORNs, where it was not possible to determine which OR they expressed (Reisert et al., 2007), and in MOR23-expressing ORNs (Lee et al., 2011).

For both M71 and mOR-EG ORNs, the latency, time to peak, and the time for the response to fall to $20 \%$ of the current value at the end of $1 \mathrm{~s}$ stimulation $\left(t_{20}\right)$ were significantly slower in OMP $\mathrm{KO}$ ORNs (Fig. $1 C$, left and right columns respectively; $\left.{ }^{*} p<0.05,{ }^{* *} p<0.005\right)$. While both kinetics were affected in the same way for ORNs expressing either OR, maximal peak responses were only reduced in the mOR-EG ORNs lacking OMP compared with the WT (Fig. 1C, right column) at the acetophenone and eugenol concentrations $(100 \mu \mathrm{M})$ used. Thus, response magnitude might be controlled by OMP in an OR-dependent manner, a question more deeply investigated below.

ORNs fire APs during the rising phase of the receptor current and they can be displayed by filtering the odorant responses at a wider bandwidth (Fig. $1 A, B$, insets). Typically an ORN fires $1-2$ APs, which we recorded as action currents at the onset of odor responses in ORNs expressing either OR, but M71-expressing ORNs in OMP KOs prolonged their spike train and fired more APs while no changes were observed in the mOR-EG ORNs, indicating that OMP controls not only the response magnitude but also the AP pattern sent to the OB. In conclusion, the differences in the odorant responses between OMP WTs and KOs indicate an involvement of OMP in signal transduction that is dependent on the expressed OR.

\section{OMP's contribution to the dynamic range of odorant sensitivity in ORNs}

Interestingly, we found differences in the peak amplitude at the single high odorant concentration of $100 \mu \mathrm{M}$ only in the mOREG-expressing ORNs while no change was observed in the M71-expressing ORNs. A previous report showed that mOR23expressing ORNs of OMP KO mice have similar peak responses compare to WT mice (Lee et al., 2011). We further investigated response magnitudes at different concentrations in a dosedependent manner. Stimulations with a series of $1 \mathrm{~s}$ pulses with 

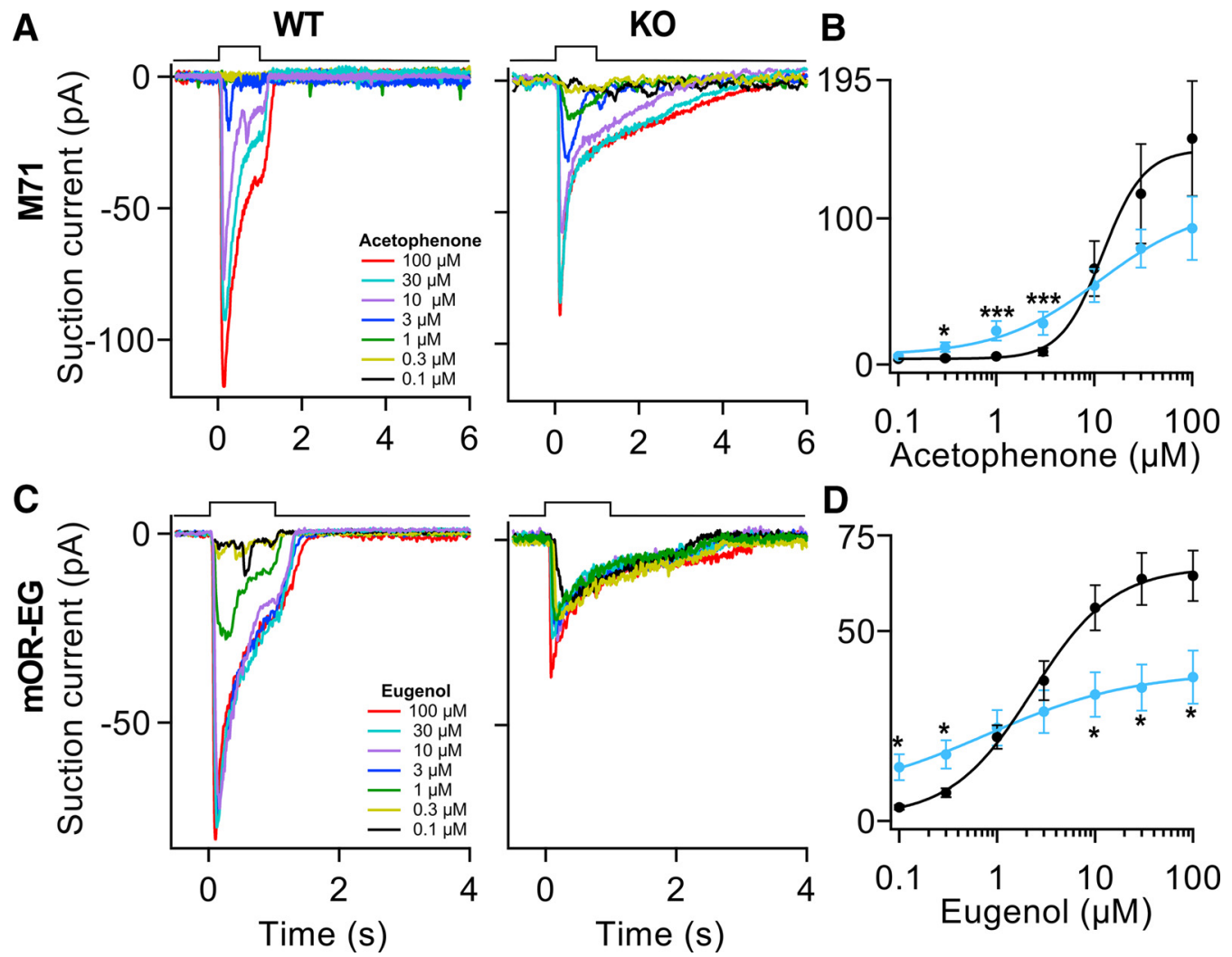

Figure 2. OMP regulates odorant sensitivity. $\boldsymbol{A}$, Acetophenone responses from OMP WT and K0 M71-expressing ORNs stimulated at increasing concentration from 0.3 to $100 \mu$ M. $\boldsymbol{B}$, The dose-response curve indicates that at 0.3, 1, and $3 \mu \mathrm{m}$ the peak amplitudes were 2.7-fold, fourfold, and threefold larger in the 0MP K0 (blue curve) M71-expressing 0RNs than in the 0MP WTs (black curve). $n=6-7$ ORNs. C, Eugenol responses from m0R-EG-expressing ORNs stimulated at increasing concentration. $D$, In this case we observed $4-5$-fold larger responses at 0.1 and $0.3 \mu m$ in the OMP KOs (blue trace) and on average twofold smaller at 10,30, and $100 \mu \mathrm{M} . n=14-22$ ORNs. ${ }^{*} p<0.05,{ }^{* * *} p<0.005$, unpaired Student's $t$ test. All data are expressed as mean \pm SEM.

acetophenone at different concentrations revealed that M71 ORNs in OMP KO mice have significantly larger responses at the low concentrations of $0.3,1$, and $3 \mu \mathrm{M}$ (Fig. $2 B$; ${ }^{*} p<0.05$, ${ }^{* *} p<$ $0.005)$. We now observed odorant responses in the OMP KOs at concentrations at which WT ORNs had not reached response threshold yet. A fit of the dose-response curves with a Hill function gave values for the $K_{1 / 2}$ (concentration for half-maximal current activation) not significantly different between WT and $\mathrm{KO}$ mice (Fig. 1B; WT, $14 \pm 2 \mu \mathrm{M}$; KO, $14 \pm 9 \mu \mathrm{M}$ ). More interestingly, the Hill coefficient was twofold smaller for the M71 OMP KO mice, indicating a broadening of their dynamic range and a less steep dose-response relationship (Fig. $1 B$; WT, $2.2 \pm$ 0.3 ; KO, $0.61 \pm 0.07 ; p<0.005)$. For both WT and KO M71expressing ORNs, we did not see full saturation of the doseresponse relation and maximal odorant responses were not significantly different as was the case in mOR-EG ORNs. We avoided higher acetophenone concentrations. It could be interesting to use a more effective M71 agonist (e.g., 2-amono-acetophenone; Zhang et al., 2012).

We wanted to understand whether the difference in response amplitude in mOR-EG OMP KOs, obtained by stimulating ORNs with eugenol at concentrations of $100 \mu \mathrm{M}$, was indicative of a shift and/or a broadening of the dynamic range of their sensitivity. Indeed, testing mOR-EG ORNs with an increasing series of different eugenol concentrations (Fig. 2C) showed an increase of the peak responses at the two lowest concentrations $\left(0.1\right.$ and $\left.0.3 \mu \mathrm{M} ;{ }^{*} p<0.05\right)$ and a decrease at the three higher concentrations $\left(10,30,100 \mu \mathrm{M} ;{ }^{\star} p<0.05\right)$ in the OMP KOs, leading to a "crossing over" of the dose-response relationship of
OMP KO and WT ORNs. Even though it appeared that the doseresponse curve lost its typical sigmoid shape (Fig. 2D) in the OMP KOs, we could still fit a Hill curve and found that the $\mathrm{K}_{1 / 2}$ value was $\sim 5$-fold smaller compared with the WTs (WT, $3.3 \pm 2.5 \mu \mathrm{M}$; $\mathrm{KO}, 0.8 \pm 0.2 \mu \mathrm{M} ; p<0.005)$. The Hill coefficient was also smaller in the OMP KOs (WT, $1.4 \pm 0.2 ; \mathrm{KO}, 0.75 \pm 0.12 ; p<$ $0.01)$. This demonstrates that the dose-response curve is flattened in the OMP KOs as if the lack of OMP diminished the contrast in the mOR-EG-expressing ORNs. Thus changes in odorant concentration only led to small changes in receptor current and ORNs partly lost their ability to distinguish among different odorant concentrations. But it should also be pointed out that OMP KO ORNs expressing either the M71 or mOR-EG OR showed an increased sensitivity at low odorant concentrations compared the WT ORNs, a result that seems counterintuitive given that OMP KO mice have a reported lower behavioral sensitivity (Youngentob and Margolis, 1999; Youngentob et al., 2001, 2003).

To further investigate this conundrum and the change in the dose-response curves in the OMP KOs and in particular the change of the Hill coefficient, we stimulated mOR-EG-expressing ORNs with $10 \mu \mathrm{M}$ eugenol at increasing pulse durations ranging from $30 \mathrm{~ms}$ to $1 \mathrm{~s}$ (Fig. $3 A, B$ ). It has been established that ORNs integrate the stimulus over time (Firestein et al., 1993; Bhandawat et al., 2005) with longer exposures giving rise to larger responses. WT ORNs integrate quickly and even at the shortest pulse duration already yielded a more-than-half maximal response (Fig. $3 A, C)$. In contrast, in the OMP KOs, shorter pulses revealed a large reduction in the peak amplitude with only little, if any, 
A

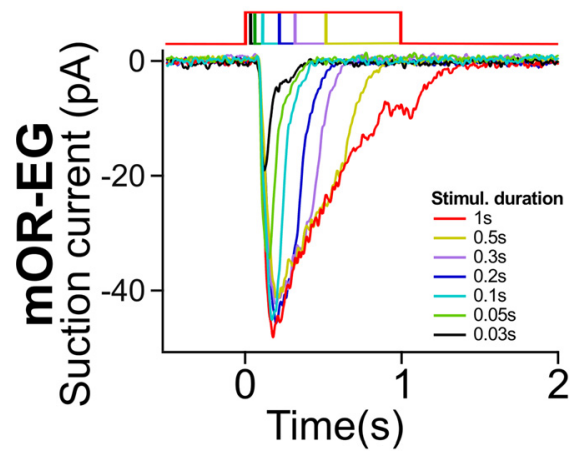

C

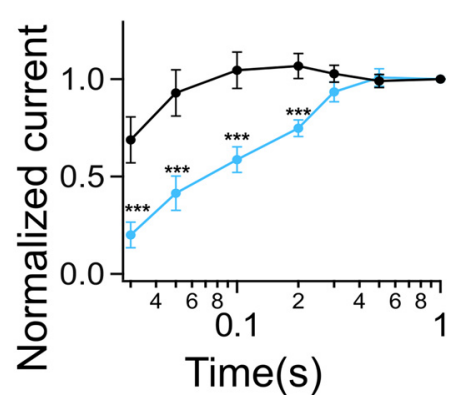

B
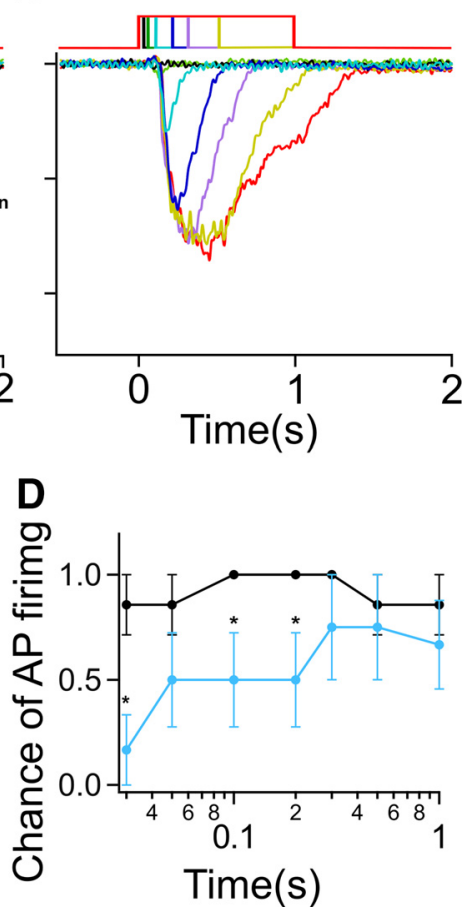

Figure 3. OMP ensures fast integration of the stimulus over time. $\boldsymbol{A}, \boldsymbol{B}$, Eugenol-induced (10 $\mu \mathrm{M})$ currents from 0MP WT $(\boldsymbol{A})$ and OMP KO ( $\boldsymbol{B}$ ) mOR-EG ORNs. Stimulus duration ranged from 0.03 to 1 s. $\boldsymbol{C}, \boldsymbol{D}$, Normalized suction current and the likelihood to fire APs as a function of stimulus duration. $A$ " 1 " or a " 0 " was given for each stimulation if APs were or were not generated. For a given stimulus duration, these values were averaged across cells to give a "chance of firing." At 0.03, 0.1, and 0.1 s, 0MP KO ORNs were less likely to generate APs $\left(\chi^{2}\right.$ test, $\left.{ }^{*} p=0.01\right) . n=6-11$. All data are expressed as mean \pm SEM.

Thus at high stimulation frequencies [e.g., during high-frequency sniffing when the stimulus duration is short during the short inhalation phase $(\sim 50 \mathrm{~ms})]$ information transferred to the bulb would be expected to be compromised.

So how does the change in the kinetics of the odorant response and AP firing in OMP KO mice affect the ORNs' ability to follow stimulation frequencies that recapitulate breathing and exploratory sniffing? ORNs in the nasal cavity are subject to continuous changes of the odor stimulation frequency due to changes in the breathing rate. WT ORNs are able to reliably encode resting respiratory patterns $(2 \mathrm{~Hz}$; Tankersley et al., 1994) at intermediate odorant concentrations (Ghatpande and Reisert, 2011) but miss or filter out some stimuli at higher frequencies $(5 \mathrm{~Hz})$. We exposed mOR-EG-expressing ORNs first to eugenol at $2 \mathrm{~Hz}$, followed by stimulation at $5 \mathrm{~Hz}$ (Fig. 4) to simulate a sniff bout. The stimulus duration was kept at $0.1 \mathrm{~s}$ in both cases and seven concentrations were tested. WT mOR-EG-expressing ORNs reliably fired APs at 1,3 , and 10 $\mu \mathrm{M}$ eugenol with near $100 \%$ reliability when delivered at a rate of $2 \mathrm{~Hz}$ (Fig. $4 A, C)$. Moreover, at $2 \mathrm{~Hz}$ we could ob-

current generated at $30 \mathrm{~ms}$ pulse duration and only reached similar and saturated response magnitudes as WT ORNs at $300 \mathrm{~ms}$. Further increases in pulse duration did not yield larger responses. Thus, OMP ensures fast integration of the stimulus over time as it reduces the response latency and accelerates the rising phase of the response. Interestingly, while the decay phase of the response is greatly slowed in the absence of OMP, larger responses can still be observed during longer pulse durations in the OMP KOs, because now ORNs are stimulated long enough to allow integration of the slow OMP KO response. These results suggest that for $1 \mathrm{~s}$ stimulation, the response to low concentrations of eugenol in the KOs was the result of the transduction events integrating over the course of the longer stimulation. In summary, OMP shortens the integration time. It means that OMP, by shortening the response latency, ensures that an ORN at shorter odorant exposure first will generate a response and then will generate a maximal response, even at those shorter pulse durations.

\section{The lack of OMP disrupts ORN coding for rapid odor sampling}

Given our observations of the reduction in suction current at short stimulus durations in the OMP KOs, we next investigated how AP generation is affected and therefore what information is sent to the OB. Figure $3 D$ shows the chance of AP firing generated for a given pulse duration. For WT ORNs, this likelihood is nearly $100 \%$ at all durations at a given pulse duration, while in OMP KO ORNs the likelihood was greatly reduced for short pulses (Fig. $3 D ;{ }^{\star} p<0.05$ Pearson's $\chi^{2}$ test). The decrease in chance of firing for shorter pulses will lead to a reduction of the signals that ORNs send to the brain, suggesting that indeed OMP is required for reliable AP coding. serve individual receptor current responses elicited by stimulation at each concentration (except for the lowest ones), but when switching to $5 \mathrm{~Hz}$ individual responses became less obvious as consecutive responses begin to fuse to give rise to a more steady-state current, rather than a dynamically regulated current. The firing probability decreased to $20 \%$, indicating the inability of mOR-EG-expressing ORNs to follow rapid stimulation trains (Fig. $4 A, D)$. At low $(0.1$ and $0.3 \mu \mathrm{M})$ and saturating concentrations ( 30 and $100 \mu \mathrm{M}$ ), the ORNs' ability to reliably code for stimulations remained generally low. mOR-EG ORNs of OMP KO mice were not able to reliably fire APs either at 2 or at $5 \mathrm{~Hz}$ stimulation rates and the chance of APs generated was near zero. With the exception of the 0.1 and $100 \mu \mathrm{M}$, the AP firing probability remained significantly lower in the ORNs of the OMP KO mice (Fig. $4 C, D ;{ }^{* *} p<0.005$ ).

The limiting factor for ORNs to fire APs in response to high-frequency stimulation is the time required for response termination at the end of an odor application (Ghatpande and Reisert, 2011). The main contributor to response termination in WT ORNs is the rate of $\mathrm{Ca}^{2+}$ extrusion from olfactory cilia determined mainly by NCKX4 (Stephan et al., 2012). The results presented in this paper and those previously published (Reisert et al., 2007; Kwon et al., 2009) showed a slower response termination in the OMP KO ORNs. If so, the slow termination phase is responsible for "fusing" of responses to consecutive stimulations in OMP KOs, thus making mOREG-expressing ORNs unable to follow high-frequency and even low-frequency train pulses. In the case of the OMP KOs, though, the deficits in response terminations were not caused by changing the rate of $\mathrm{Ca}^{2+}$ extrusion but rather by the lack of OMP in speeding up the cAMP dynamics (Reisert et al., 
2007). Thus, by increasing the response speed, OMP contributes to improved detection of stimuli during repetitive and fast stimulations.

\section{Involvement of OMP in cAMP dynamics}

To probe how OMP is participating in cAMP dynamics in ORNs, we used IBMX, a PDE inhibitor, to reveal AC3 activity in the absence of odor stimulation. In randomly picked ORNs expressing unknown ORs, IBMX elicited larger responses (Reisert et al., 2007) in the OMP KOs, indicative of higher basal AC3 activity and cAMP levels in the absence of stimulation. Puzzlingly, M71-expressing ORNs (Fig. $5 A, C$, left column) showed an unexpected behavior, which is that the size of IBMX responses in the OMP KOs were similar to that of the WTs, suggesting similar basal cAMP levels in the absence of stimulation. By contrast, mOR-EG ORNs generated a larger response upon IBMX stimulation in the OMP KOs (Fig. 5B). The IBMX peak amplitude is on average 10 -fold higher in the OMP KOs compared with WTs. It should be noted that in mOR-EG ORNs, the responses to IBMX are usually small or even absent due to the low basal activity of mOR-EG (Reisert, 2010; Fig. 5C, left column black bar; $\left.{ }^{* * *} p<0.005\right)$. Indeed, in our case only $45 \%$ of OMP WT mOR-EG ORNs responded to IBMX and among those only $20 \%$ had a response amplitude $>2 \mathrm{pA}$. By comparison, $90 \%$ of $\mathrm{mOR}-\mathrm{EG}$ ORNs in the OMP KOs responded to IBMX and all with current amplitude $>2 \mathrm{pA}$. These results show that the differences in IBMX responses were OR dependent. The lack of OMP caused an increase of the basal level of cAMP, further indicating a role for OMP in early events of the signal transduction (Reisert et al., 2007). In particular, the increase in cAMP basal levels is evident only in mOR-EG and not M71 ORNs as we could not detect any significant difference in M71 ORNs between OMP WTs and KOs. A parsimonious explanation is that in M71 ORNs the basal level of cAMP is already high, creating a ceiling effect so that in the absence of OMP a further increase in cAMP levels is not able to increase significantly the overall IBMX response (see Discussion).

To investigate the contribution of OMP to maintaining low basal levels of cAMP and its functional consequences, we exposed ORNs to the PDE inhibitor IBMX for $8 \mathrm{~s}$, followed immediately by a $1 \mathrm{~s}$ odor stimulation. By stimulating with IBMX and inhibiting PDE, thus blocking basal cAMP degradation, ORNs should attain an adapted state. This would lead to a reduction of the odorant response after IBMX exposure compared with the one lacking IBMX pre-exposure. Figure $6 A$ shows that indeed after $8 \mathrm{~s}$ IBMX stimulation of a WT M71 ORN, the acetophenone response (black trace) is reduced compared with the odorant response without IBMX pre-exposure (gray trace). The situa-
B KO

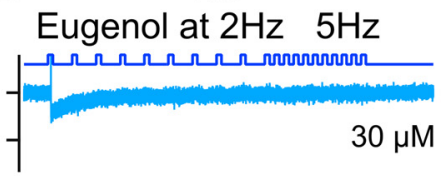

$30 \mu \mathrm{M}$
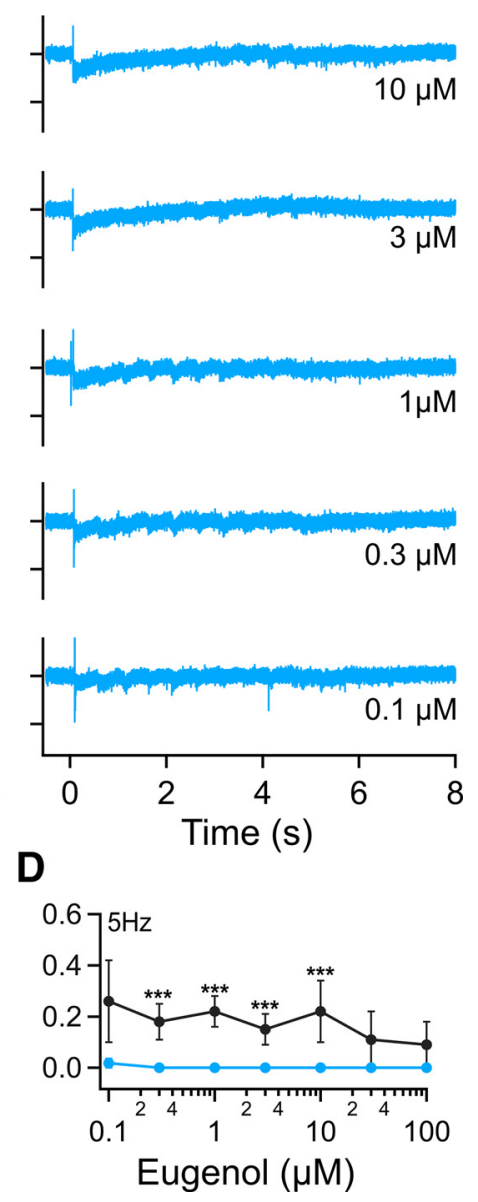

Figure 4. Disrupted AP firing patterns during 2 and $5 \mathrm{~Hz}$ stimulations in OMP KO ORNs. $A, B$, Recordings from ORNs expressing the $\mathrm{mOR}$-EG receptor $(\boldsymbol{A}, \mathrm{WT} ; \boldsymbol{B}, 0 \mathrm{MP}$ KO) , stimulated at increasing concentrations of eugenol. Stimuli at $2 \mathrm{~Hz}$ were followed by $5 \mathrm{~Hz}$; of APs was divided by the number of stimulations to yield the firing probability at $2(C)$ and $5 \mathrm{~Hz}$ (D). OMP WT firing probability is represented with black lines and markers. OMP KO firing probability is represented with blue lines and markers. $n=6-7$ ORNs; ${ }^{*} p<0.05 ;{ }^{* * *} p<0.005$, unpaired Student's $t$ test. All data are expressed as mean \pm SEM.

tion was similar in M71 OMP KO ORNs (Fig. 6B). In both cases the reduction in the acetophenone response after IBMX pre-exposure was $\sim 40 \%$ (Fig. $6 E$ ).

A different situation emerged when the same experimental protocol was applied to mOR-EG ORNs where, in WT ORNs, only small responses were elicited by $8 \mathrm{~s}$ IBMX (Fig. $6 \mathrm{C}$, black trace) and consequently the following eugenol response was reduced only by $15 \%$ (compared with a eugenol response without IBMX pre-exposure). In the OMP KOs, the mOR-EG ORN showed a large response to IBMX pre-exposure and the following odorant response was now $35 \%$ smaller than the response in the absence of IBMX, a reduction similar to the one observed in M71 ORNs.

The data were analyzed by plotting the ratio (Fig. $6 E$ ) of the IBMX response and the odorant response in the absence of IBMX pre-exposure against the ratio of the odorant responses with and without IBMX pre-exposure. The first is a measure of the size of the IBMX-induced response, the latter a measure of the adapta- 

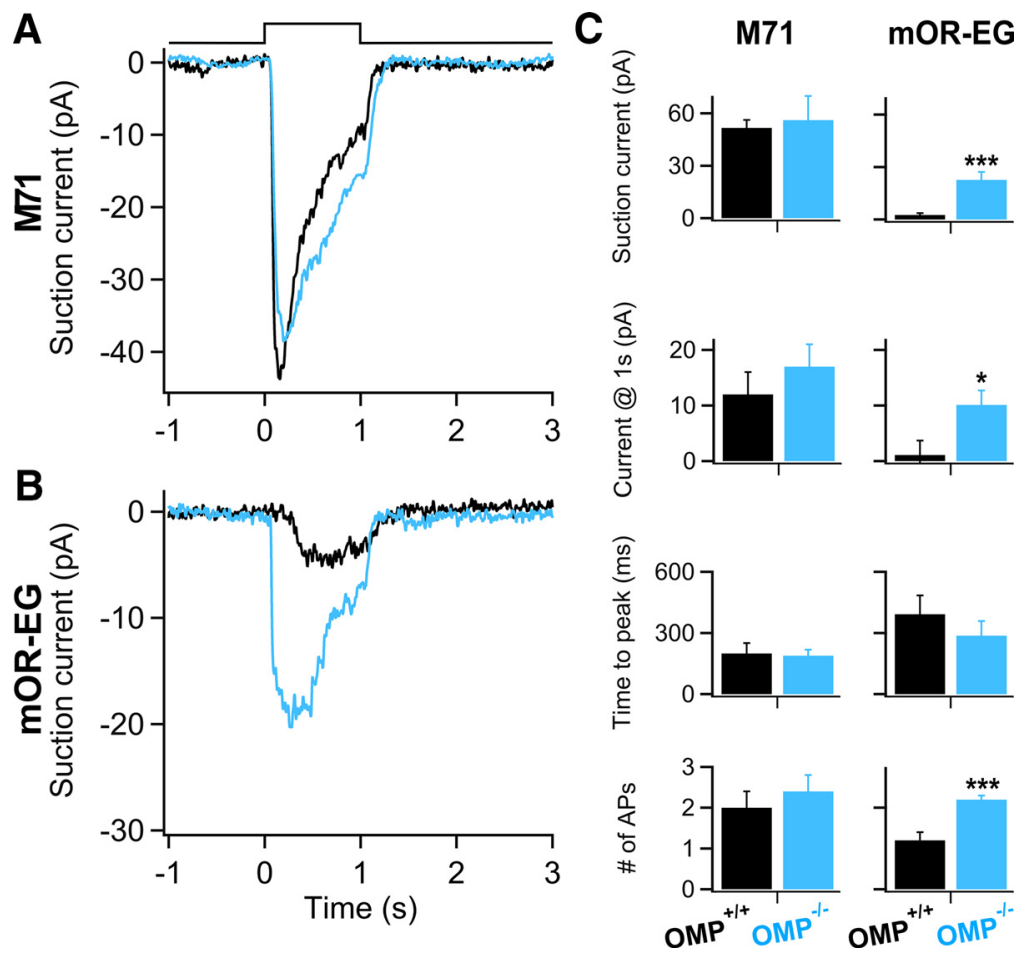

Figure 5. Odorant-receptor-dependent responses to PDE inhibitor IBMX. A, Responses to a $1 \mathrm{~s}$ stimulation of $1 \mathrm{~mm}$ of the PDE inhibitor IBMX from M71-GFP OMP WT and OMP KO (black and blue trace) ORNs. None of the parameters measured was significantly different ( $C$, left column). $n=10-14 . B, 1$ s IBMX stimulation of mOR-EG-GFP OMP WT and OMP KO ORNs. mOR-EG GFP OMP KO peak responses were significantly larger than those of mOR-EG-GFP OMP KO ORNs. The current at the end of the $1 \mathrm{~s}$ (Current @ 1s) stimulation is indicative of a larger residual current at the end of the stimulation as a result of an altered termination phase of OMP KOs (C, right column). mOR-EG-GFP OMP KO ORNs also fire twice as many APs than OMP WTs. $n=5-14$ ORNs. ${ }^{*} p<0.05$; ${ }^{* * *} p<0.005$, unpaired Student's $t$ test. All data are expressed as mean \pm SEM.

tion occurring upon PDE blockage. Figure $6 E$ shows that while responses of M71 ORNs remained largely unchanged by knocking out OMP, mOR-EG ORN responses of OMP KO mice are greatly reduced compared with those of OMP WT mice. In particular mOR-EG ORNs of OMP KO mice (Fig. 6E, cyan empty circle) have approximately the same values as those of M71 ORNs of OMP WT and $\mathrm{KO}$ mice (Fig. 6E, black and cyan filled circle respectively). From these results we can conclude that OMP is controlling cAMP dynamics and homeostasis by modifying cAMP levels according to the receptor that an ORN is expressing, especially in ORNs that have a low level of basal activity, like the mOR-EG OR.

The increase of the IBMX response in the mOR-EG OMP KO ORNs is the result of higher basal levels of cAMP due to an increase of the spontaneous activity of possibly all components of the signal transduction cascade. In particular an increase in IBMX responses could be observed if the expression of AC3 is higher in the OMP WT mice than in OMP KO mice. To test whether this is the case, we used NKH-477, an analog of forskolin, which is an AC3 activator, at $40 \mu \mathrm{M}$ (Satake et al., 1998) and found no differences in NKH-477-induced responses in the mOR-EG-expressing ORNs in the OMP KO mice compared with the OMP WT mice (data not shown; peak current: WT, $50.5 \pm 15.2 \mathrm{pA} ; \mathrm{KO}, 37 \pm 12 \mathrm{pA}, p=0.44>0.05$, $n=4-5)$. Therefore it is unlikely that simply a higher level of AC3 expression or a more active form of the enzyme contributed to the higher cAMP response in the OMP KOs. This suggests that OMP acts as a "brake" on the spontaneous activity of transduction components involved in cAMP dy- namics, maybe by modifying the basal rate at which cAMP is produced.

\section{OMP affects basal noise in ORN}

We previously established that the OR itself is the major contributor to noise in WT ORNs (Reisert, 2010). So we then asked whether the differences in the basal activity of mOR-EG and M71 might help to explain some of the OR-dependent changes occurring in the OMP KOs. In other words, we wanted to address how basal activity of ORs alters ORN physiology in WT and OMP KO mice. The two ORs chosen have low (mOR-EG) and high (M71) basal activity respectively as can be seen in Figure 7A,C. M71expressing ORNs in the OMP WTs fired at a basal rate of $\sim 0.7 \mathrm{~Hz}$ (Fig. $7 F$ ) in contrast to mOR-EG-expressing ORNs, which show a very low, near zero, basal firing rate. Basal noise is largely caused by the spontaneous activation of the OR (Reisert J 2010), which leads to the activation of the transduction cascade and eventually to APs (Fig. 7A-D, 0-30 s). Spontaneous APs can be silenced by blocking the $\mathrm{Ca}^{2+}$-activated $\mathrm{Cl}^{-}$channel TMEM16B/ ANO2 with niflumic acid (Fig. $7 A-D$, $30-60 \mathrm{~s})$. The higher the level of spontaneous events, the larger is the IBMX response (as before mentioned, IBMX blocks PDE, therefore revealing the basal levels of CAMP). We determined the noise level over a $0.3-50 \mathrm{~Hz}$ bandwidth of the power spectrum in the absence of niflumic acid subtracted by the one with niflumic acid (as shown previously in Reisert, 2010; see Materials and Methods). Noise levels showed a relationship with the response to the PDE inhibitor IBMX (Fig. 7E). Two striking changes occurred in the M71 OMP KOs. First, the lack of OMP greatly reduced noise levels (Fig. $7 E$; variance: WT, $0.65 \pm 0.18 \mathrm{pA}^{2}$; KO, $0.13 \pm 0.05$ $\mathrm{pA}^{2} ; p<0.05$, unpaired Student's $t$ test), but did not alter the response to IBMX (Fig. 7E; $p>0.05$, unpaired Student's $t$ test). This could be explained by the observation that lack of OMP greatly prolongs the odorant response and therefore also the shot noise-like currents observed in M71 ORNs in the WTs. These fast events would be slowed in the OMP KOs, would begin to fuse and be transformed into more of a standing current, and would therefore not be observed as noise any longer. But a constant stimulation at a low level would still give rise to IBMX-evoked currents. This is consistent with or similar to the observed fusing of responses during rapid odorant stimulation (Fig. 4). The second striking observation is the reduction in basal AP firing in M71 OMP KO ORNs (Fig. 7F, blue filled symbols; WT, $0.71 \pm 0.27$ $\mathrm{Hz}$; KO, $0.025 \pm 0.02 \mathrm{~Hz} ; p<0.05$ unpaired Student's $t$ test). This again can be explained with a more tonic basal current in the KOs compared with the more phasic, shot noise-like currents in the WTs. The latter does generate APs, while a more constant current is thought not to.

We observed increased IBMX responses in mOR-EG OMP KO ORNs (Figs. 5B, 6C), which correspond to an increase in the variance. Indeed, the variance in mOR-EG ORNs in OMP KOs was 15-fold larger than that in the OMP WTs (Fig. 7E, black 

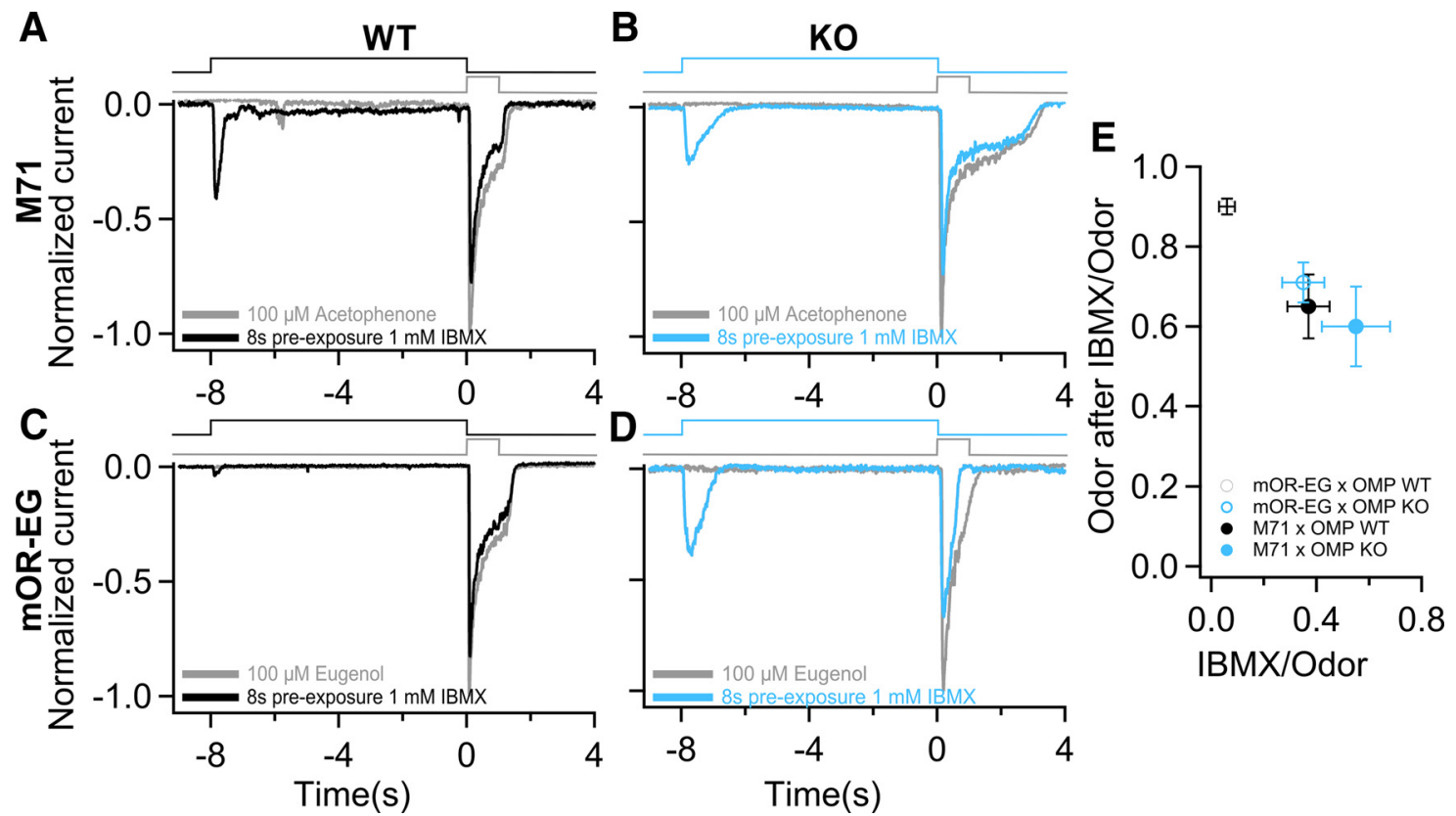

Figure 6. OMP affects basal state of adenylyl cyclase. $\boldsymbol{A}, \boldsymbol{B}$, Both M71 OMP WT and KO ORNs were exposed for $1 \mathrm{~s}$ to acetophenone with (cyan trace) or without (gray trace) an $8 \mathrm{~s}$ pre-exposure to IBMX.C, D, Same experiments were performed with eugenol on mOR-EG-GFP ORNs. $E$, The odorant response after IBMX exposure divided by the control odorant response as a function of the IBMX response relative to the odorant response. Open circles indicates mOR-EG ORNs while filled circle are for M71 ORNs. $n=13-14$ for M71 0RNs; $n=16-23$ for mOR-EG ORNs. Values are significantly different: ${ }^{*} p<0.005$, unpaired Student's $t$ test. All data are expressed as mean \pm SEM.

empty circles, $p<0.05$ unpaired Student's $t$ test) with noise reaching levels similar to those in M71 OMP KOs. The increase of the IBMX response can therefore be explained by the increase in the basal noise. As in the case of M71 ORNs, the lack of OMP leads to larger and slower spontaneous events that alter both response kinetics and amplitude (Fig. 1). It should be noted that in the absence of OMP, mOR-EG and M71 ORNs have similar low basal firing rates that are essentially indistinguishable (Fig. $7 F$ ). This suggests that OMP plays a major role in maintaining appropriate and different basal activity across ORNs expressing different ORs.

\section{OMP is not directly involved in} glomerular targeting and positioning So far we showed that OMP is involved in regulating cAMP dynamics in the absence of stimulation and during the odorant response. OMP's involvement is even more evident in ORNs expressing an OR with low basal activity, such as mOR-EG. Beside its role in signal transduction, CAMP is important for the correct targeting of ORN axons to specific glomeruli in the OB. In particular, recent results have shown that basal levels of cAMP are involved in anterior-posterior positioning of glomeruli in the OB. Each OR, having its own basal activity, determines the basal concentration of cAMP, which in turn determines the expression levels of guidance

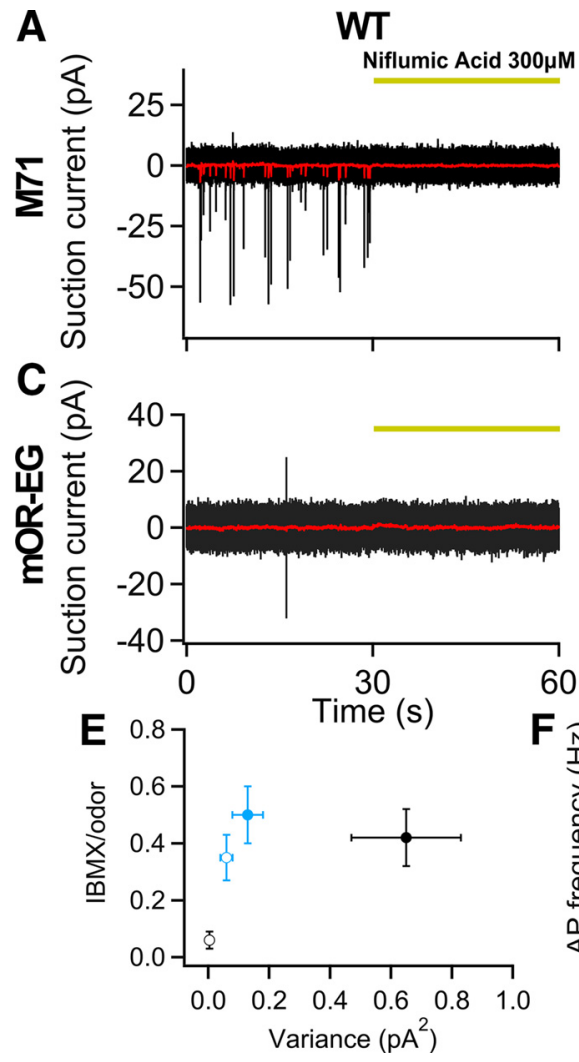

B KO
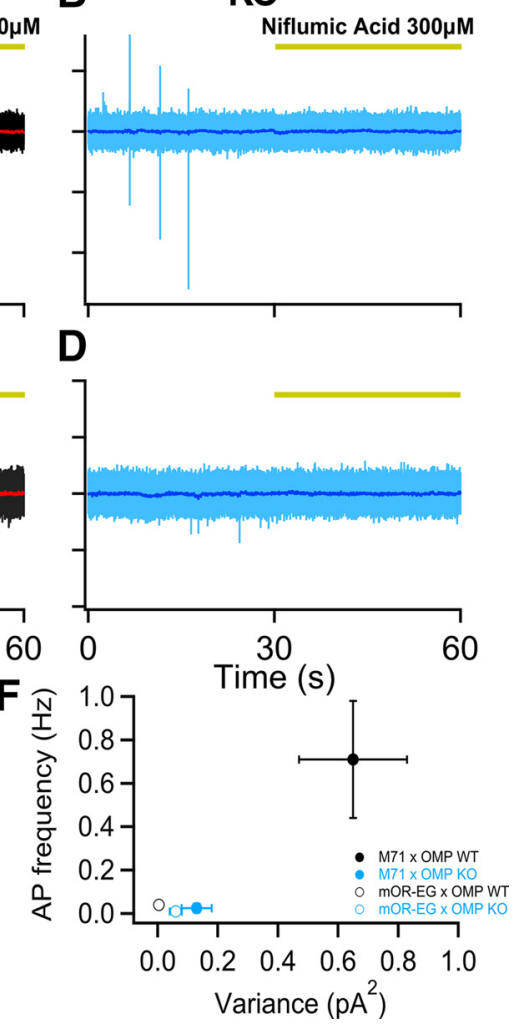

Figure 7. $0 M P$ alters spontaneous activity in an odorant-receptor-dependent manner. $\boldsymbol{A}-\boldsymbol{D}$, Baseline recordings in absence of stimulation from M71 OMP WTs $(\boldsymbol{A})$ and OMP KOs $(\boldsymbol{B})$ and mOR-EG OMP WTs $(\boldsymbol{C})$ and OMP KOs $(\boldsymbol{D})$. The red and dark blue traces represent low-pass filtered $(50 \mathrm{~Hz})$ recordings. The $\mathrm{Ca}^{2+}$-activated $\mathrm{Cl}^{-}$channel blocker niflumic acid at $300 \mu \mathrm{M}$ abolished basal activity. $E$, mOR-EG and M71 IBMX $(1 \mathrm{mM}, 1 \mathrm{~s})$ responses were normalized to the responses of their respective ligand at $100 \mu \mathrm{m}$. The ratio is then plotted against the basal variance (averages of $8-240 \mathrm{RNs}$ ). $\boldsymbol{F}$, Average basal spike firing rate as a function of the basal variance $(n=8-10$ ORNs). All data are expressed as mean \pm SEM. 

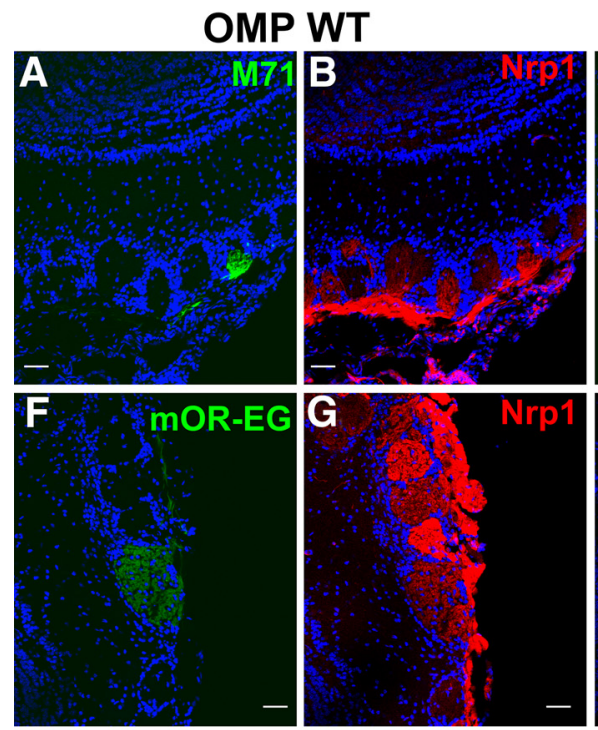
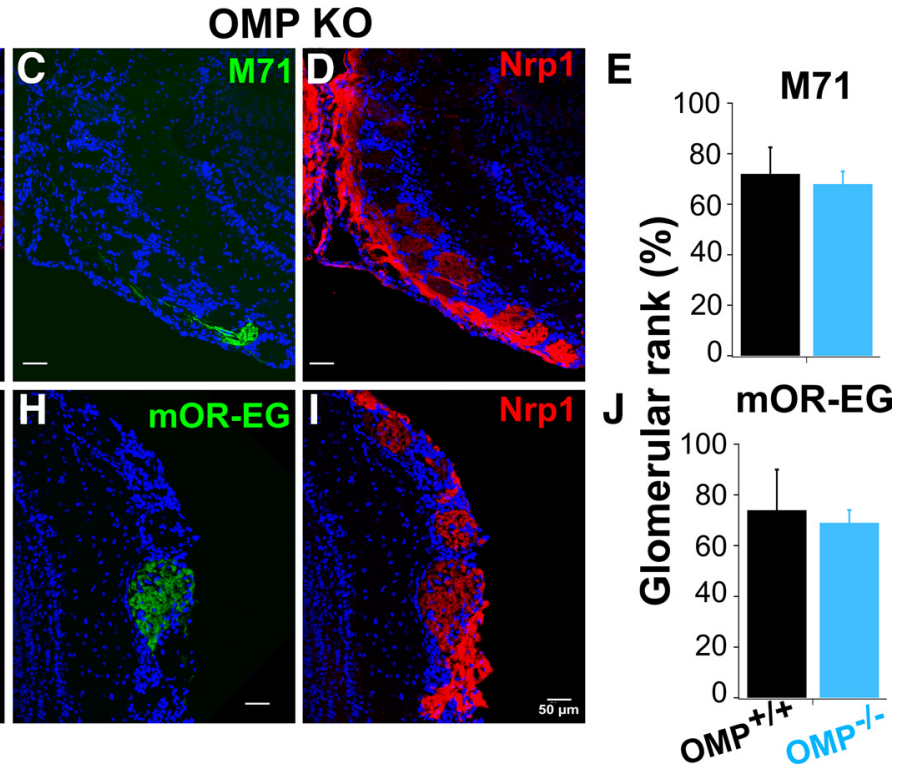

Figure 8. Axonal targeting and Nrp1 expression in the OB. $A, C, F, H, G F P$-expressing M71 or m0R-EG glomeruli in OMPWTs $(\boldsymbol{A}, \boldsymbol{F})$ and $\operatorname{KOs}(\boldsymbol{C}, \boldsymbol{H}) \cdot \boldsymbol{B}, \boldsymbol{D}, \boldsymbol{G}, \boldsymbol{I}, \mathrm{Nrp} 1$ staining in the $0 B$ revealed mosaic patterns in both OMP WTs and KOs and for both receptor types (B, D: M71; G, I: mOR-EG). For comparison $\sim 100$ glomeruli for each mouse ( $n=5$ and $n=7$ mice for M71 0MP WTs and KOs respectively and for mOR-EG OMPWTs and KOs; $n=2$ mice for each genotype). $E$-J, Glomeruli were ranked and Nrp1 levels of GFP-positive glomeruli fell into the $\sim 70^{\text {th }}$ percentile in all genotypes tested. $p>0.05$, Wilcoxon rank sum test. All data are expressed as mean \pm SEM.

molecules (Nakashima et al., 2013). Neuropilin 1 (Nrp1), a semaphorin class 3 receptor, is involved in such a mechanism and is dependent on the basal cAMP levels in ORNs expressing different ORs (Imai et al., 2006; Nakashima et al., 2013). In general, the dependence of Nrp1 on cAMP is also evident in AC3 KO mice, where the levels of Nrp1 are drastically reduced (Col et al., 2007), compared with WT mice, and where ORN axons grossly miss their targets. We reasoned that if cAMP is altered in OMP KO mice during the establishment of glomerular targeting, we should find defects in targeting in those mice. We investigated Nrp1 expression in the $\mathrm{OB}$ and potential defects in glomerular formation. We stained consecutive sections of OBs with an antibody raised against Nrp1. First, we observed a mosaic pattern of Nrp1 expression in sagittal section of the OB. Glomeruli showed high, low, or even absent levels of Nrp1 (Fig. $8 B-D, G-I$ ) and we did not observe any substantial changes in the staining pattern in the OMP KO bulbs (measured as cumulative probability of the staining intensity of $\sim 100$ glomeruli for each mouse; data not shown). The GFP-positive glomeruli, which were innervated by either the mOR-EG or M71 ORN axons, had very similar Nrp1 expression both in the OMP WTs and KOs for the two different ORs (Fig. $8 A-E$, for M71 glomeruli, $F-J$ for mOR-EG glomeruli). There were no differences as to where the M71 OMP WTs and M71 KOs ranked from the highest Nrp1-staining intensity among the glomeruli analyzed (Fig. 8E). No differences either were found between mOR-EG OMP WTs and OMP KOs (Fig. $8 \mathrm{~J}$ ), although one might have expected to see a change in the MOR-EG glomeruli given the above results of increased responses to IBMX.

These results were further confirmed by the absence of shift of the M71 glomeruli along the anterior-posterior axis of the $\mathrm{OB}$ in OMP KOs, as expected since no change in Nrp1 levels were observed. Determination of the position of mOR-EG glomeruli was not attempted, as a single bulb often displayed $\leq 11$ mOR-EGpositive glomeruli, making comparison between WTs and KOs ambiguous. In summary, in the OB of the OMP KO mice we did not detect any gross defects in targeting: both M71 and mOR-EGexpressing ORNs were able to form properly innervated glomer- uli in the medial and lateral side of the $\mathrm{OB}$ and the guidance molecule, Nrp1, is expressed in similar ways in OMP WTs and OMP KOs.

\section{Discussion}

OMP is expressed in mature chemosensory neurons in the nasal cavity and its mechanisms of action depending on the OR expressed in a given ORN has not been investigated. In ORNs, cAMP can be produced by spontaneous activation of the OR, which drives Golf to stimulate AC3 with subsequent opening of $\mathrm{CNG}$ and $\mathrm{Ca}^{2+}$-activated $\mathrm{Cl}^{-}$channels. Interestingly, ORs have varying levels of basal activity (Reisert, 2010; Connelly et al., 2013; Nakashima et al., 2013) and hence we chose to investigate the mOR-EG and the M71 OR as they have respectively low and high levels of spontaneous activity and therefore low and high levels of basal cAMP. The latter is particularly interesting as OMP has been implicated in the kinetic regulation of cAMP (Reisert et al., 2007). In overall agreement with previous reports, we found that knocking out OMP prolongs response onset, rising phase, and response termination of the odorant-induced response regardless of the expressed OR. The previously observed prolonged odorant-induced AP train in OMP KO mice (Reisert et al., 2007) was only observed in M71-expressing ORNs, but not in mOREG-expressing ORNs, indicating that indeed OMP might modulate basal and odorant-induced cAMP dynamics in an OR-dependent way. An involvement of OMP in $\mathrm{Ca}^{2+}$ extrusion by interacting with the $\mathrm{Na}^{+}-\mathrm{Ca}^{2+}$ exchanger has been shown to take place in ORN dendritic knobs (Kwon et al., 2009). Interestingly $\mathrm{Ca}^{2+}$ is also sequestered by mitochondria in the knob (Fluegge et al., 2012), and similar to OMP KOs, disabling mitochondrial $\mathrm{Ca}^{2+}$ sequestration prolongs the odorant response and longer stimulus durations are required for ORNs to reach firing threshold. However, our results show that lack of OMP broadens the dose-response relation, while lack of mitochondrial $\mathrm{Ca}^{2+}$ homeostasis in the knob steepens the dose-response curve. This suggests a more complex role of OMP and its contribution to ORN responses in cilia and knobs. As our experiments are re- 
stricted to monitoring ciliary events, the interplay between OMP, $\mathrm{Na}^{+}-\mathrm{Ca}^{2+}$ exchange, and mitochondrial knob $\mathrm{Ca}^{2+}$ homeostasis remains to be investigated.

We found that in the absence of OMP, the basal current noise driven by these two receptors, which is sevenfold different in the WT, is almost the same (Fig. 7). In mOR-EGexpressing ORNs, the increased levels of cAMP (larger IBMX responses in OMP KOs) leads to an increase in noise while in M71 ORNs knocking out OMP has the opposite effect, so lack of OMP ablates the difference in noise levels and basal AP firing between these two ORs. Moreover, in mOR-EG OMP KO ORNs, the increase in IBMX response together with the slower odorant-response kinetics are indicative of OMP lowering basal cAMP production inside the cilia. In the absence of OMP, continuous cAMP production and low-level activation of the transduction cascade lead to ORNs being in an adapted state (Reisert and Matthews, 1999; Reisert et al., 2007). This cAMP increase in the OMP KO is not predominantly driven by basal activity of the OR, since we especially observed an increase in noise and IBMX response in mOR-EG ORNs, which lack basal OR-driven noise. This indicates that one of OMP's roles is that of synchronizing basal activity of AC3 with that of the OR an ORN expresses, and OR-constitutive activity becomes the dominant source of noise. In this way OR monogenic expression together with its particular basal activity can now play different instructive roles in ORN physiology in the olfactory system (e.g., dictating the position of glomeruli in the bulb).

Moreover, basal cAMP needs to be maintained at correct concentrations to ensure an appropriate trade-off between sensitivity and cooperativity during the odorant response. In the OMP WT, ORNs do not respond to lower odorant concentrations used here and the steepness of their dose-response curve allows for a proper detection and discrimination of odorants at intermediate concentration. Surprisingly, knocking out OMP reveals that ORNs are able to respond to these low odorant concentrations, probably by integrating (see below) the small, but now slower, responses over the $1 \mathrm{~s}$ stimulus duration. This, on the one hand, makes ORNs more sensitive, but also, as the dose-response relation is now much shallower, makes it harder to encode the odorant concentration. It also suggests that ORs bind and are activated by odorants at much lower concentrations ( $>1 \log$ unit) than one would assume from the odorant-current dose-response relation. Moreover, ORNs integrate the stimulus over time (Firestein et al., 1990) and, when OMP is absent, ORNs integrate much more slowly. Now odorant stimulations with the duration of a typical inhalation period (50-100 ms) are often not sufficient to activate ORNs (Fig. 3). In summary, while for longer stimulation OMP allows ORNs to narrow its dynamic range, for shorter stimulation OMP speeds up integration time so that ORNs can increase their chance of firing APs.

A possible explanation for the increased AC3 activity and increased cAMP levels in the OMP KO ORNs that we observed by using IBMX could be a compensatory mechanism through which AC3 becomes more abundant (Lee et al., 2011). The reported increase in protein levels in the OMP KO does not seem to affect responses to the AC3 activator NKH 477, suggesting that functional AC3 activity is not increased in the OMP KO compared with the WT. OMP could modify AC3 phosphorylation (Lee et al., 2011), although this seems unlikely as phosphorylation does not seem to affect odorant response termination (Cygnar et al., 2012).
cAMP basal levels have been reported to drive glomerular positioning along the anterior-posterior axis in the OB (Imai et al., 2006; Chesler et al., 2007; Nakashima et al., 2013). We sought to determine whether the altered level of basal noise could also alter those processes. Nrp1, an anterior-posterior targeting molecule that is dependent on spontaneously generated cAMP, is altered neither in its expression level nor in its distribution across the bulbs. Our data, thus, suggest that OMP is not involved in glomerular targeting, most likely because OMP is only expressed at a later stage of ORN development when cAMP-derived signals have already established the position of a given glomerulus (Nakashima et al., 2013; Rodriguez-Gil et al., 2015).

\section{From single-cell physiology to behavior}

Given the much shallower dose-response relation and the slow integration of the stimulus in the OMP KOs, we investigated how ORNs lacking OMP respond to a stimulus paradigm that resembles sniffing patterns in vivo. Previously (Ghatpande and Reisert, 2011) and here, we could show that ORNs can reliably generate APs following stimulation patterns of $2 \mathrm{~Hz}$. However, this fidelity is lost at $5 \mathrm{~Hz}$. In the OMP KOs, ORNs are not able to fire APs during 2 or $5 \mathrm{~Hz}$ stimulation. We noticed in particular that their prolonged response termination does not allow ORNs to fully recover from depolarization and to fire APs to subsequent stimuli. By speeding up the termination phase of the transduction current, OMP facilitates cellular repolarization so that an ORN is ready to fire APs at the next stimulation to reliably send odorant information to the OB. Moreover, OMP enables ORNs to function as stimulus frequency-dependent filters able to generate APs with high fidelity at $2 \mathrm{~Hz}$ and silencing it, at least in part, at higher-frequency $(5 \mathrm{~Hz})$ stimulations, thus acting as a low-pass filter. It is tempting to speculate that a slowed odorant response unable to generate APs in the OMP KO cannot synchronize odorant responses with the sniffing frequency, thus leading to deterioration of signals arriving at the bulb. Indeed, from bulb imaging experiments it seems that OMP KO mice have less total odorantevoked neurotransmitter release when assessed within the first $2 \mathrm{~s}$ of an odorant presentation, suggestive of reduced AP input during this time window. But later during the stimulation, the total neurotransmitter release was comparable to that of control mice (Kass et al., 2013). In short, in OMP KO mice OB responses take longer to fully develop. Consistently, if an OMP KO mouse engaged in an odor task has plenty of time to accomplish the task, it can perform comparably to controls (Youngentob and Margolis, 1999). Further, mice and rats are able to distinguish odorant in $\sim 200$ ms (Uchida and Mainen, 2003; Abraham et al., 2004; Rinberg et al., 2006), which can be $\leq 2$ sniffing cycles at high sniffing rates. Thus the failure of proper AP synchronization with the sniffing cycle could impair odor-dependent behaviors.

In summary, we show that OMP reduces the AC3-induced noise in ORNs and thus helps to maintain appropriate basal levels of cAMP across ORs with different spontaneous activation (i.e., mOR-EG and M71). OMP also speeds up the odorant response with important consequences. It allows ORNs to maintain better fidelity when exposed rapidly to successive odorant stimulations by first integrating the odor stimulus rapidly and then by terminating the response quickly. OMP also ensures a dynamic doseresponse relation at the cost of suppressing responses at low odorant concentrations, thus steeping the dose-response relation. The latter is further improved as OMP WT ORNs are able to generate larger maximal responses compared with KO ORNs. Thus, by tuning noise and response kinetics, OMP is a key regulator of ORN physiology. It will be interesting to investigate 
whether OMP might also play a similar role in other tissues, given its recently reported broader expression pattern (Kang et al., 2015).

\section{References}

Abraham NM, Spors H, Carleton A, Margrie TW, Kuner T, Schaefer AT (2004) Maintaining accuracy at the expense of speed. Neuron 44: 865-876. CrossRef Medline

Bakalyar HA, Reed RR (1990) Identification of a specialized adenylyl cyclase that may mediate odorant detection. Science 250:1403-1406. CrossRef Medline

Baylor DA, Matthews G, Yau KW (1980) Two components of electrical dark noise in toad retinal rod outer segments. J Physiol 309:591-621. CrossRef Medline

Bhandawat V, Reisert J, Yau KW (2005) Elementary response of olfactory receptor neurons to odorants. Science 308:1931-1934. CrossRef Medline

Billig GM, Pál B, Fidzinski P, Jentsch TJ (2011) $\mathrm{Ca}^{2+}$-activated $\mathrm{Cl}^{-}$currents are dispensable for olfaction. Nat Neurosci 14:763-769. CrossRef Medline

Boccaccio A, Lagostena L, Hagen V, Menini A (2006) Fast adaptation in mouse olfactory sensory neurons does not require the activity of phosphodiesterase. J Gen Physiol 128:171-184. CrossRef Medline

Bozza T, Feinstein P, Zheng C, Mombaerts P (2002) Odorant receptor expression defines functional units in the mouse olfactory system. J Neurosci 22:3033-3043. Medline

Buck L, Axel R (1991) A novel multigene family may encode odorant receptors: a molecular basis for odor recognition. Cell 65:175-187. CrossRef Medline

Buiakova OI, Baker H, Scott JW, Farbman A, Kream R, Grillo M, Franzen L, Richman M, Davis LM, Abbondanzo S, Stewart CL, Margolis FL (1996) Olfactory marker protein (OMP) gene deletion causes altered physiological activity of olfactory sensory neurons. Proc Natl Acad Sci U S A 93: 9858-9863. CrossRef Medline

Chesler AT, Zou DJ, Le Pichon CE, Peterlin ZA, Matthews GA, Pei X, Miller MC, Firestein S (2007) A G protein/cAMP signal cascade is required for axonal convergence into olfactory glomeruli. Proc Natl Acad Sci U S A 104:1039-1044. CrossRef Medline

Col JA, Matsuo T, Storm DR, Rodriguez I (2007) Adenylyl cyclasedependent axonal targeting in the olfactory system. Development 134 : 2481-2489. CrossRef Medline

Connelly T, Savigner A, Ma M (2013) Spontaneous and sensory-evoked activity in mouse olfactory sensory neurons with defined odorant receptors. J Neurophysiol 110:55-62. CrossRef Medline

Cygnar KD, Zhao H (2009) Phosphodiesterase 1C is dispensable for rapid response termination of olfactory sensory neurons. Nat Neurosci 12: 454-462. CrossRef Medline

Cygnar KD, Collins SE, Ferguson CH, Bodkin-Clarke C, Zhao H (2012) Phosphorylation of adenylyl cyclase III at serine1076 does not attenuate olfactory response in mice. J Neurosci 32:14557-14562. CrossRef Medline

Dzeja C, Hagen V, Kaupp UB, Frings S (1999) $\mathrm{Ca}^{2+}$ permeation in cyclic nucleotide-gated channels. EMBO J 18:131-144. CrossRef Medline

Firestein S, Shepherd GM, Werblin FS (1990) Time course of the membrane current underlying sensory transduction in salamander olfactory receptor neurones. J Physiol 430:135-158. CrossRef Medline

Firestein S, Zufall F, Shepherd GM (1991) Single odor-sensitive channels in olfactory receptor neurons are also gated by cyclic nucleotides. J Neurosci 11:3565-3572. Medline

Firestein S, Picco C, Menini A (1993) The relation between stimulus and response in olfactory receptor cells of the tiger salamander. J Physiol 468:1-10. CrossRef Medline

Fluegge D, Moeller LM, Cichy A, Gorin M, Weth A, Veitinger S, Cainarca S, Lohmer S, Corazza S, Neuhaus EM, Baumgartner W, Spehr J, Spehr M (2012) Mitochondrial $\mathrm{Ca}^{(2+)}$ mobilization is a key element in olfactory signaling. Nat Neurosci 15:754-762. CrossRef Medline

Gesteland RC, Sigwart CD (1977) Olfactory receptor units-a mammalian preparation. Brain Res 133:144-149. CrossRef Medline

Ghatpande AS, Reisert J (2011) Olfactory receptor neuron responses coding for rapid odour sampling. J Physiol 589:2261-2273. CrossRef Medline

Hengl T, Kaneko H, Dauner K, Vocke K, Frings S, Möhrlen F (2010) Molecular components of signal amplification in olfactory sensory cilia. Proc Natl Acad Sci U S A 107:6052-6057. CrossRef Medline
Imai T, Suzuki M, Sakano H (2006) Odorant receptor-derived cAMP signals direct axonal targeting. Science 314:657-661. CrossRef Medline

Jones DT, Reed RR (1989) Golf: an olfactory neuron specific-G protein involved in odorant signal transduction. Science 244:790-795. CrossRef Medline

Kajiya K, Inaki K, Tanaka M, Haga T, Kataoka H, Touhara K (2001) Molecular bases of odor discrimination: reconstitution of olfactory receptors that recognize overlapping sets of odorants. J Neurosci 21:6018-6025. Medline

Kang N, Kim H, Jae Y, Lee N, Ku CR, Margolis F, Lee EJ, Bahk YY, Kim MS, Koo J (2015) Olfactory marker protein expression is an indicator of olfactory receptor-associated events in non-olfactory tissues. PLoS One 10: e0116097. CrossRef Medline

Kass MD, Moberly AH, McGann JP (2013) Spatiotemporal alterations in primary odorant representations in olfactory marker protein knockout mice. PLoS One 8:e61431. CrossRef Medline

Kepecs A, Uchida N, Mainen ZF (2007) Rapid and precise control of sniffing during olfactory discrimination in rats. J Neurophysiol 98:205-213. CrossRef Medline

Kleene SJ (1993) Origin of the chloride current in olfactory transduction. Neuron 11:123-132. CrossRef Medline

Kwon HJ, Koo JH, Zufall F, Leinders-Zufall T, Margolis FL (2009) $\mathrm{Ca}^{2+}$ extrusion by NCX is compromised in olfactory sensory neurons of $\mathrm{OMP}^{-\prime-}$ mice. PLoS One 4:e4260. CrossRef Medline

Lee AC, He J, Ma M (2011) Olfactory marker protein is critical for functional maturation of olfactory sensory neurons and development of mother preference. J Neurosci 31:2974-2982. CrossRef Medline

Lowe G, Gold GH (1991) The spatial distributions of odorant sensitivity and odorant-induced currents in salamander olfactory receptor cells. J Physiol 442:147-168. CrossRef Medline

Lowe G, Gold GH (1993) Nonlinear amplification by calcium-dependent chloride channels in olfactory receptor cells. Nature 366:283-286. CrossRef Medline

Malnic B, Hirono J, Sato T, Buck LB (1999) Combinatorial receptor codes for odors. Cell 96:713-723. CrossRef Medline

Margolis FL (1972) A brain protein unique to the olfactory bulb. Proc Natl Acad Sci U S A 69:1221-1224. CrossRef Medline

Matthews HR (1999) A compact modular flow heater for the superfusion of mammalian cells. J Physiol 518:13P. CrossRef

Nakamura T, Gold GH (1987) A cyclic nucleotide-gated conductance in olfactory receptor cilia. Nature 325:442-444. CrossRef Medline

Nakashima A, Takeuchi H, Imai T, Saito H, Kiyonari H, Abe T, Chen M, Weinstein LS, Yu CR, Storm DR, Nishizumi H, Sakano H (2013) Agonist-independent GPCR activity regulates anterior-posterior targeting of olfactory sensory neurons. Cell 154:1314-1325. CrossRef Medline

Oka Y, Katada S, Omura M, Suwa M, Yoshihara Y, Touhara K (2006) Odorant receptor map in the mouse olfactory bulb: in vivo sensitivity and specificity of receptor-defined glomeruli. Neuron 52:857-869. CrossRef Medline

Ponissery Saidu S, Dibattista M, Matthews HR, Reisert J (2012) Odorantinduced responses recorded from olfactory receptor neurons using the suction pipette technique. J Vis Exp e3862. CrossRef Medline

Rasche S, Toetter B, Adler J, Tschapek A, Doerner JF, Kurtenbach S, Hatt H, Meyer H, Warscheid B, Neuhaus EM (2010) Tmem16b is specifically expressed in the cilia of olfactory sensory neurons. Chem Senses 35: 239-245. CrossRef Medline

Reisert J (2010) Origin of basal activity in mammalian olfactory receptor neurons. J Gen Physiol 136:529-540. CrossRef Medline

Reisert J, Matthews HR (1999) Adaptation of the odour-induced response in frog olfactory receptor cells. J Physiol 519:801-813. CrossRef Medline

Reisert J, Matthews HR (2001) Response properties of isolated mouse olfactory receptor cells. J Physiol 530:113-122. CrossRef Medline

Reisert J, Yau KW, Margolis FL (2007) Olfactory marker protein modulates the cAMP kinetics of the odour-induced response in cilia of mouse olfactory receptor neurons. J Physiol 585:731-740. CrossRef Medline

Rinberg D, Koulakov A, Gelperin A (2006) Speed-accuracy tradeoff in olfaction. Neuron 51:351-358. CrossRef Medline

Rodriguez-Gil DJ, Bartel DL, Jaspers AW, Mobley AS, Imamura F, Greer CA (2015) Odorant receptors regulate the final glomerular coalescence of olfactory sensory neuron axons. Proc Natl Acad Sci U S A 112:5821-5826. CrossRef Medline 
Rospars JP, Lansky P, Chaput M, Duchamp-Viret P (2008) Competitive and noncompetitive odorant interactions in the early neural coding of odorant mixtures. J Neurosci 28:2659-2666. CrossRef Medline

Sagheddu C, Boccaccio A, Dibattista M, Montani G, Tirindelli R, Menini A (2010) Calcium concentration jumps reveal dynamic ion selectivity of calcium-activated chloride currents in mouse olfactory sensory neurons and TMEM16b-transfected HEK 293T cells. J Physiol 588:4189-4204. CrossRef Medline

Satake K, Takagi K, Kodama I, Honjo H, Toyama J, Shibata S (1998) Relaxant effects of NKH477, a new water-soluble forskolin derivative, on guinea-pig tracheal smooth muscle: the role of $\mathrm{Ca}^{2+}$-activated $\mathrm{K}^{+}$channels. Br J Pharmacol 123:753-761. CrossRef Medline

Stephan AB, Shum EY, Hirsh S, Cygnar KD, Reisert J, Zhao H (2009) ANO2 is the cilial calcium-activated chloride channel that may mediate olfactory amplification. Proc Natl Acad Sci U S A 106:11776-11781. CrossRef Medline

Stephan AB, Tobochnik S, Dibattista M, Wall CM, Reisert J, Zhao H (2012) The $\mathrm{Na}^{(+)} / \mathrm{Ca}^{(2+)}$ exchanger NCKX4 governs termination and adaptation of the mammalian olfactory response. Nat Neurosci 15:131-137. CrossRef Medline
Tankersley CG, Fitzgerald RS, Kleeberger SR (1994) Differential control of ventilation among inbred strains of mice. Am J Physiol 267:R1371R1377. Medline

Uchida N, Mainen ZF (2003) Speed and accuracy of olfactory discrimination in the rat. Nat Neurosci 6:1224-1229. CrossRef Medline

Youngentob SL, Margolis FL (1999) OMP gene deletion causes an elevation in behavioral threshold sensitivity. Neuroreport 10:15-19. CrossRef Medline

Youngentob SL, Mozell MM, Sheehe PR, Hornung DE (1987) A quantitative analysis of sniffing strategies in rats performing odor detection tasks. Physiol Behav 41:59-69. CrossRef Medline

Youngentob SL, Margolis FL, Youngentob LM (2001) OMP gene deletion results in an alteration in odorant quality perception. Behav Neurosci 115:626-631. CrossRef Medline

Youngentob SL, Kent PF, Margolis FL (2003) OMP gene deletion results in an alteration in odorant-induced mucosal activity patterns. J Neurophysiol 90:3864-3873. CrossRef Medline

Zhang J, Huang G, Dewan A, Feinstein P, Bozza T (2012) Uncoupling stimulus specificity and glomerular position in the mouse olfactory system. Mol Cell Neurosci 51:79-88. CrossRef Medline 